\title{
COVID-19 Vaccine, Contraceptive, Viscosity and Safety Margin Change
}

\author{
Sora Yasri 1,*iD, Viroj Wiwanitkit ${ }^{2}$ (D) \\ 1 Private Academic Consultant, Bangkok Thailand; sorayasri@outlook.co.th (S.Y.); \\ 2 Dr DY Patil University, Pune, India; wviroj@yahoo.com (V.W.); \\ * Correspondence: sorayasri@otlook.co.th (S.Y.);
}

Scopus Author ID 56022182600

Received: 19.06.2021; Revised: 25.07.2021; Accepted: 28.07.2021; Published: 5.09.2021

\begin{abstract}
COVID-19 vaccine is the new vaccine aiming at containment of the COVID-19 outbreak. For vaccination, an interaction with personal medication is an important concern. Since the contraceptive pill is widely used and the interrelationship with the COVID-19 vaccine is possible. A study to assess interrelationship is interesting. Clinical mathematical model analysis is used to estimate viscosity change comparing COVID-19 vaccine recipients with and without contraceptive use. A safety margin value for no hyperviscosity is also calculated. A decreased safety margin for no hyperviscosity is expected in one who takes a contraceptive pill. It is necessary to monitor for blood viscosity change in vaccine recipients who use the contraceptive pill, and if it is possible, the contraceptive pill should be stopped before vaccination.
\end{abstract}

Keywords: COVID-19; vaccine; contraceptive.

(C) 2021 by the authors. This article is an open-access article distributed under the terms and conditions of the Creative Commons Attribution (CC BY) license (https://creativecommons.org/licenses/by/4.0/).

\section{Introduction}

COVID-19 is a present global public health crisis that is still existed worldwide [1-3]. The new COVID-19 vaccine is the new tool for the management of pandemics [4-6]. Since the COVID-19 vaccine is new and is registered in emergency mode, there are limited data on efficacy and safety [7-9]. The adverse effects of any vaccine are possible, and there are sporadic reports for the COVID-19 vaccine [10-12].

The vaccination in subjects with underlying disease or personal medication might cause the interaction between new vaccine and underlying disease or personal medication, and there might be an unwanted clinical consequence. Regarding personal contraceptive pill, it is widely used for fertility control among fertile age women, and it is in the interrelationship between contraceptive pill with COVID-19 vaccine is possible. A study to assess interrelationship is interesting. In this study, the authors assess the rheological impact of the contraceptive pill. Post COVID-19, blood viscosity change is estimated, and change of safety margin for no hyperviscosity is also calculated.

\section{Materials and Methods}

This is a clinical mathematical model study. The assessment of blood viscosity change is done based on the basic clinical rheological principle. Basically, blood viscosity depends on two important compositions, plasma and cellular components. A new COVID-19 vaccine can induce rapid immunoglobulin production in blood. Immunoglobulin is a protein and can cause 
an increased level of viscosity. An estimated increasing viscosity level from normal background value in a healthy person is $2.4 \mathrm{cp}$ [13]. An alteration of viscosity after vaccination will cause no problem if viscosity does not exceed the hyperviscosity cut-off level, equal to 5 cp [14].

For a clinical mathematical model study, the estimation of final viscosity after COVID19 vaccination is done. A simulation is performed for 2 scenarios, a) vaccine recipient without contraceptive pill use and b) vaccine recipient without contraceptive pill use. Regarding the effect of contraceptive pill use, primary data of blood viscosity change due to contraceptive pill in a previous referencing report is referred to [15]. The estimated final viscosity will be equal to "background viscosity + change after receiving COVID-19 vaccine with/without contraceptive pill use". Then a calculation for a safety margin for no problem of hyperviscosity is done.

Basically, there will be a safety margin for no hyperviscosity problem in anyone receiving the vaccine. A safety margin is defined as a value representing a difference between the final estimated viscosity and hyperviscosity cut-off level. Therefore, it can be calculated by "hyperviscosity cut-off level - estimated final viscosity".

This study is a pure clinical mathematical stud and does not involve animals or humans; it requires no ethical approval.

\section{Results and Discussion}

From clinical mathematical model analysis, the estimated safety margin values are presented in Table 1. According to this study, there is a difference of safety margin for no hyperviscosity between COVID-19 vaccine recipients with and without contraceptive use. A COVID-19 vaccine recipient with contraceptive use has a lower safety margin value.

Table 1. Safety margin of COVID-19 vaccine recipient with and without contraceptive use.

\begin{tabular}{l|c|c} 
Group & $\begin{array}{c}\text { Background } \\
\text { viscosity value (cp) }\end{array}$ & $\begin{array}{c}\text { Estimated safety } \\
\text { margin (cp) }\end{array}$ \\
\hline $\begin{array}{l}\text { vaccine recipient with } \\
\text { contraceptive use }\end{array}$ & 1.58 & 0.92 \\
\hline $\begin{array}{l}\text { vaccine recipient without } \\
\text { contraceptive use entry 2 }\end{array}$ & 1.40 & 1.10
\end{tabular}

Adverse effect following COVID-19 vaccination is an important publication consideration at present. Of several possible adverse effects, rheological alteration is a commonly reported issue. Clot and thromobohostatic problems might follow COVID-19 vaccination [16-18]. Alteration of blood viscosity is an important result of the interaction between an administered vaccine and human physiology. If there is a personal medication, the interaction between the vaccine and personal medication is a very important issue.

Here, the authors discuss the impact of contraceptive use. At present, there is no study to assess the effect of contraceptives. According to this study, it can show an impact of viscosity in case there is the concurrent use of both contraceptive pill and COVID-19 vaccine. Clinically, the increased blood viscosity in women using oral contraceptive pills was reported [19]. Hence, there is no doubt that there might be an increased risk if COVID-19 concurrently uses the contraceptive pill. 


\section{Conclusions}

Hyperviscosity is an important adverse clinical problem due to the COVID-19 vaccine. The vaccine can induce immune production and result in increased viscosity. In a situation that there is the concurrent use of the contraceptive pill, a significantly increased viscosity is expected. This might result in a clotting problem due to hyperviscosity. As a clinical recommendation, it is necessary to monitor for blood viscosity change in COVID-19 vaccine recipient who has contraceptive pill as personal medication. If it is possible, the contraceptive pill should be ceased before the COVID-19 vaccination.

\section{Funding}

This research received no external funding.

\section{Acknowledgments}

This research has no acknowledgment.

\section{Conflicts of Interest}

The authors declare no conflict of interest.

\section{References}

1. Adil, M.T.; Rahman, R.; Whitelaw, D.; Jain, V.; Al-Taan, O.; Rashid, F.; Munasinghe, A.; Jambulingam, P. SARS-CoV-2 and the pandemic of COVID-19. Postgrad Med J 2021, 97, 110-116, https://doi.org/10.1136/postgradmedj-2020-138386.

2. Hsia, W. Emerging new coronavirus infection in Wuhan, China: situation in early 2020. Case Study Case Rep 2020, 10, 8-9.

3. Yasri, S.; Wiwanitkit, V. Editorial: Wuhan coronavirus outbreak and imported case. Adv Trop Med Pub Health Int 2019, 9, 1-2.

4. Wang, J.; Peng, Y.; Xu, H.; Cui, Z.; Williams. R.O. 3rd. The COVID-19 Vaccine Race: Challenges and Opportunities in Vaccine Formulation. AAPS PharmSciTech 2020, 21, https://doi.org/10.1208/s12249-02001744-7.

5. Zhao, J.; Zhao, S.; Ou, J.; Zhang, J.; Lan, W.; Guan, W.; Wu, X.; Yan, Y.; Zhao, W.; Wu, J.; Chodosh, J.; Zhang, Q. COVID-19: Coronavirus Vaccine Development Updates. Front Immunol 2020, 11, https://doi.org/10.3389/fimmu.2020.602256.

6. Hodgson, S.H.; Mansatta, K.; Mallett, G.; Harris, V.; Emarym K.R.W.; Pollard, A.J. What defines an efficacious COVID-19 vaccine? A review of the challenges assessing the clinical efficacy of vaccines against SARS-CoV-2. Lancet Infect Dis 2021, 21, e26-e35, https://doi.org/10.1016/S1473-3099(20)30773-8.

7. Calina. D.; Docea, A.O.; Petrakis, D.; Egorov, A.M.; Ishmukhametov, A.A.; Gabibov, A.G.; Shtilman, M.I.; Kostoff, R.; Carvalho, F.; Vinceti, M.; Spandidos, D.A.; Tsatsakis, A. Towards effective COVID-19 vaccines: Updates, perspectives and challenges (Review). Int J Mol Med, 2020, 46, 3-16, https://doi.org/10.3892/ijmm.2020.4596.

8. Kaur, S.P.; Gupta, V. COVID-19 Vaccine: A comprehensive status report. Virus Res 2020, 288, https://doi.org/10.1016/j.virusres.2020.198114.

9. Sharma. O.; Sultan, A.A.; Ding, H.; Triggle C.R. A Review of the Progress and Challenges of Developing a Vaccine for COVID-19. Front Immunol 2020, 11, https://doi.org/10.3389/fimmu.2020.585354.

10. Haynes, B.F.; Corey, L.;Fernandes, P.; Gilbert, P.B.; Hotez, P.J,; Rao, S.; Santos, M.R., Schuitemaker, H.; Watson, M.; Arvin, A. Prospects for a safe COVID-19 vaccine. Sci Transl Med 2020, 12, https://doi.org/10.1126/scitranslmed.abe0948.

11. CDC COVID-19 Response Team; Food and Drug Administration. Allergic Reactions Including Anaphylaxis After Receipt of the First Dose of Pfizer-BioNTech COVID-19 Vaccine - United States, December 14-23, 2020. MMWR Morb Mortal Wkly Rep 2021, 70, 46-51, https://doi.org/10.15585/mmwr.mm7002e1.

12. Lambert, P.H.; Ambrosino, D.M.; Andersen, S.R.; Baric, R.S.; Black, S.B.; Chen, R.T.; Dekker, C.L.; Didierlaurent, A.M.; Graham, B.S.; Martin, S.D.; Molrine, D.C.; Perlman, S.; Picard-Fraser, P.A.; Pollard, A.J.; Qinm C.; Subbarao, K.; Cramerm, J.P. Consensus summary report for CEPI/BC March 12-13, 2020 
meeting: Assessment of risk of disease enhancement with COVID-19 vaccines. Vaccine 2020, 38, 4783-4791, https://doi.org/10.1016/j.vaccine.2020.05.064.

13. Dalakas, M.C. High-dose intravenous immunoglobulin and serum viscosity: risk of precipitating thromboembolic events. Neurology 1994, 44, 223-6.4, https://doi.org/10.1212/wnl.44.2.223.

14. Mehta, J.; Singhalm S. Hyperviscosity syndrome in plasma cell dyscrasias. Semin. Thromb Hemost 2003, 29 , 467-71, https://doi.org/10.1055/s-2003-44554.

15. Kaibara, M.; Marumoto, Y.; Taniguchi, I.; Kobayashi, T. Clinical studies on flow properties of blood in the gynecological patients with potentially hypercoagulable state. Nihon Sanka Fujinka Gakkai Zasshi 1981, 33, 1173-9.

16. Hwang, J.; Lee, S.B.; Lee, S.W.; Lee, M.H.; Koyanagi, A.; Jacob, L.; Tizaoui, K.; Yon, D.K.; Shin, J.I.; Smith, L. Comparison of vaccine-induced thrombotic events between ChAdOx1 nCoV-19 and Ad26.COV.2.S vaccines. J Autoimmun 2021, 122, https://doi.org/10.1016/j.jaut.2021.102681.

17. Thakur, K.T.; Tamborska, A.; Wood, G.K.; McNeill, E.; Roh, D.; Akpan, I.J.; Miller, E.C.; Bautista, A.; Claassen, J.; Kim, C.Y.; Guekht, A.; Pardo, C.A.; Williams, O.; García-Azorín, D.; Prasad, K.; Schmutzhard, E.; Michael, B.D.; Chou, S.H.; Winkler, A.S.; Solomon, T.; Elkind, M.S. Clinical review of cerebral venous thrombosis in the context of COVID-19 vaccinations: Evaluation, management, and scientific questions. $J$ Neurol Sci 2021, 427, https://doi.org/10.1016/j.jns.2021.117532.

18. Hwang, J.; Lee, S.B.; Lee, S.W.; Lee, M.H.; Koyanagi, A.; Jacob, L.; Tizaoui, K.; Yon, D.K.; Shin, J.I.; Smith, L. Comparison of vaccine-induced thrombotic events between ChAdOx1 nCoV-19 and Ad26.COV.2.S vaccines. J Autoimmun 2021, 122, https://doi.org/10.1016/j.jaut.2021.102681.

19. Lowe, G.D.; Drummond, M.M.; Forbes, C.D.; Barbenel, J.C. Increased blood viscosity in young women using oral contraceptives. Am J Obstet Gynecol 1980, 137, 840-2, https://doi.org/10.1016/00029378(80)90896-0. 